\title{
Interview with M. A. K. Halliday, Cardiff, July 1998
}

\author{
Interviewers: Geoff Thompson (GT), from the University of \\ Liverpool and Heloisa Collins (HC), from the Pontifícia Uni- \\ versidade Católica de São Paulo-PUC-SP.
}

\begin{abstract}
Resumo: Esta entrevista com MAK Halliday foi conduzida durante o $25^{\circ}$ Instituto e Congresso Internacionais em Linguística Sistêmico-Funcional, realizado em Cardiff, Grä-Bretanha. A entrevista apresenta discussões muito interessantes e frequentemente inéditas sobre o desenvolvimento da teoria Sistêmico-Funcional, a relação entre a Sistêmico-Funcional e outras escolas linguísticas, a visão de $M A K$ Halliday sobre a Linguística Crítica, as relações entre linguística e cognição e a questão da relação entre Registro e Gênero. Adicionalmente, MAK Halliday toca em algumas questões teóricopráticas de análise tais como a questão da extensão do Tema e a relação entre Transitividade e Ergatividade. A entrevista termina com uma discussão sobre as dificuldades a serem superadas na análise mediada por computador, à luz da complexidade da teoria.
\end{abstract}

Abstract: This interview with MAK Halliday was conducted in Cardiff, UK, during the $25^{\text {th }}$ International Systemic Functional Institute \& Congress. The interview offers interesting discussion on traditional and new issues in Systemic Functional Linguistics, including the development of the theory, the relationship between systemic functional linguistics and other linguistic trends, MAK Halliday's views on critical linguistics, the relationship between linguistics and cognition and the relationship between Register and Genre. In addition to those issues, MAK Halliday deals with some theoretical and practical analytical issues, such as Theme, Transitivity and Ergativity. The interview closes with a discussion about difficulties to be overcome by computer-mediated analysis, in the light of the complexity of the theory. 


\section{Introduction}

This interview was conducted in Cardiff, UK, during the $25^{\text {th }}$ International Systemic Functional Institute \& Congress, when ISFC celebrated its Silver Jubilee. It was made possible thanks to MAK Halliday's friendly welcome to the proposal from the very beginning. ${ }^{1}$

The Institute took the form of a masterclass based on MAK Halliday's most important recent work at the time, An Introduction to Functional Grammar ( $\left.2^{\text {nd }} \mathrm{ed}\right)$. Taught by Halliday himself, with the assistance of Christian Matthiessen, the course offered us all a unique opportunity to revisit the main points of the theory in the light of Halliday's current thinking and to discuss issues of interest with renown systemicists: Margaret Berry, David Butt, Martin Davies, Peter Fries and Geoff Thompson.

The Congress brought together hundreds of systemicists, both new and experienced in the field, from all over the world. Speakers of Portuguese were represented by a party of fifteen researchers. Of these, half presented papers as members of DIRECT, a bi-national research project in business communication that started its activities in 1990, bringing together two teams of applied linguists. One team originated from the Applied English Language Studies Unit - AELSU, at the University of Liverpool, and included Flo Davies, Mike Hoey, Geoff Thompson, Mike Scott and Susan Thompson, among others. The other team originated from LAEL - Programa de Pós-Graduação em Linguística Aplicada e Estudos de Linguagem, at PUC-SP, and included Maria Antonieta Celani, Leila Barbara, Heloisa Collins, Rosinda Ramos, Tony Berber Sardinha and Alice Freire, among many others. Together, both teams developed theoretical and applied research and published several joint papers where SFL played a major role.

At PUC-SP, where SFL had not been established as an area of systematic studies before the DIRECT project, Halliday's thoughts and insights into language opened a new inspiring road for research. A lot of work was produced during the Direct years (over 20 thesis and dissertations, 44 working papers and countless papers published and presented in national and international conferences) and a whole new generation of applied

\footnotetext{
${ }^{1}$ I would like to take the liberty to publicly thank Geoff Thompson for his invaluable work, especially during the editing stage. H.C.
} 
linguists at LAEL was formed in the Systemic-Functional tradition. The trip to Cardiff to attend a course with MAK Halliday was, therefore, a very special treat for the Brazilian group and the object of very careful planning, which included planning this interview.

We hope you enjoy reading the interview as much as we enjoyed talking to MAK Halliday and later preparing the text for DELTA.

\section{The Interview}

\section{The development of the theory}

HC - Can I ask you first about how you see your own work as fitting into the development of linguistics as a whole, and especially language as social practice?

MAKH - I see it as part of the development of the field. I would always emphasize how much I share with other linguists: I've never either felt particularly distinct or wanted to be distinct. I never saw myself as a theorist; I only became interested in theory, in the first place, because, in the theoretical approaches that I had access to, I didn't find certain areas developed enough to enable me to explore the questions that I was interested in. For example, in Firth's work - obviously, the main influence on me was my teacher, J. R. Firth - there was a sort of hole in the middle. He did a lot of work at the phonology-phonetics end, and he did a lot of work at the context of situation end, but he didn't work with grammar. So I felt I had to develop that. But, essentially, I took his basic notions of systems and structures. And in the broader sense, I've always felt that what I was doing was very much part of the tradition - well, I should say, perhaps, part of the European tradition, because we didn't take very much from American structuralism. I did, though, draw on the Sapir-Whorf tradition in the United States - but not so much the post-Bloomfield school, which seemed more remote. And also when I came to know of Pike's work, I found that it was much more compatible with what I was doing. And then, bringing in another aspect, I was also very much influenced by my study in China, where I had been taught both traditional Chinese phonological theory, and also modern theory but as applied to Chinese linguistics. For example, I did my historical linguistics in relation 
to Sino-Tibetan, not in relation to Indo-European; and my dialectology in Chinese dialects and so on.

Now as regards the social practice, again I would feel that what I've explored has been a development of these interests. Again, it goes back to Firth, whose view was - and I think he said it in so many words - that the important direction for the future lay in the sociology of language. In the sixties, the name and the concept of socio-linguistics came into being. It was defined by somebody in the United States - I've forgotten now if this was Labov's formulation or Fishman's, or whose - as inter-relations between linguistic structure and social structure. I suppose my own thinking was a bit different from the main-stream socio-linguistics as that evolved and developed; indeed I was quite critical of it in some respects. My influence came more from Bernstein. I generally accepted his view of cultural transmissions and the framework he was using at the time: family role systems and their effect on language. He struck me as the one leading sociologist who really built language into his theory. So there was a lot of influence there, and that provided the context for my thinking on these issues.

$\mathrm{HC}$ - I remember that in one of the lectures during the institute you told us about why it was that Bernstein for a while suffered all sorts of criticism: the way he put across his ideas at the time was not completely well-received.

$\mathrm{MAKH}-\mathrm{He}$ was totally brutalized: it drove him right out of the field. I think it was mainly in the United States that his work was misunderstood, ${ }^{2}$ although that meant the picture got transmitted back

\footnotetext{
2 As Halliday points out, Basil Bernstein has had an important influence on the way in which systemic-functional linguists view the relationships between language and society. The aspect of his theory which led to the attacks on him that Halliday mentions was the idea of restricted and elaborated codes. A restricted code is the kind of language that we typically use in informal conversation with friends and family. For example, one of the features of our language in such contexts is that we do not need to make things explicit, because we can rely on the other person understanding when we talk about 'that thing over there' etc. An elaborated code is the kind of language that is used in more formal contexts (such as writing), when we need to make things more explicit - and we typically talk and write about more complex topics than in informal conversation. Bernstein argued that middle-class children had an advantage at school because they were more likely to be exposed at home not only to restricted codes but also to elaborated codes; whereas working class children were more likely to be exposed only to restricted codes at home, and therefore faced greater difficulties in coping with the language of education. Bernstein
} 
across the Atlantic and his work was misunderstood over here as well, and in many other places - although not quite universally. At that time, Ruqaiya Hasan had got interested in Bernstein's work and Bernstein invited her to join in his project along with another linguist, Geoffrey Turner, who is here at this congress; and Bernie Mohan (now in Vancouver) worked with him for a while as well. Bernstein was at the Institute of Education in London while I was at University College, so it was very easy to meet and to interact.

GT - You've talked about some of the main people that influenced you. What about the way your theory developed? What kind of stages would you see in your thinking?

MAKH - From the late fifties onwards, and particularly when I started working with teachers, I felt that I needed to get a much more secure grounding both in an overall theory, an overall model of language, and also specifically in grammar and semantics. We didn't have any semantics at that time - it was very weak. So I moved consciously in that direction, and I was saying, I'm not ready to take further the notion of language in relation to social processes until I feel more confident of what I can say about language itself. So in that period, particularly in the sixties, I spent a lot of time, first of all, exploring Chomsky's work. And I found it didn't really answer my questions, it didn't help me to explore the right kind of issues. So I moved back to what I had been doing before, originally on Chinese. I shifted over into English; and in the sixties I worked with teachers at all levels, so I became involved with the context of developing a grammar for educational purposes. Now I still saw that as a part of what I sometimes call the social accountability of the linguist - although it wasn't directly political, it was, as I saw it, trying to make a contribution to society. And also, of course, we learn a lot about language from being involved in practical applications like this. I had this group in London, which I think must have been about the only time that somebody had got a research and development project where there were primary and secondary and tertiary

\footnotetext{
emphasized that both codes were equally good at serving their intended function, and saw his work as providing a basis for more enlightened and effective approaches to education (cf. what Halliday says later about 'giving value to varieties of language that were traditionally neglected'). However, his views were mistakenly or maliciously interpreted by many critics as being a snobbish claim that working class children were less intelligent and inherently unable to master the elaborated codes required for advancement in the society.
} 
teachers all in the same room, all doing the same job and working together. We spent about two years learning to talk to each other, finding out what each other was on about. That was immensely valuable.

By that time, of course, what I was doing in the core areas of language had very little value among linguists: it wasn't recognized. So I thought, OK, now in any case is it time to turn back to the social? And I tried to develop this notion of social semiotics. I did a lot of work in the seventies where I was moving away from the grammar and other core areas and saying, right, now let's look again at what is outside language and see if I can make contact there, but in a different perspective. And then in the eighties I centred my writing again on the grammar. I thought, right, let's see how far we can make explicit a systembased grammar, but now with the semantics in it. By that time there were a number of people who were working in systemic computational linguistics. Up to about 1980, I had got involved a few times trying to test bits of the grammar computationally, but we didn't learn anything from it. We hadn't got to that stage yet; but from about 1980, with fifth generation computers, the computer became a real research tool. There was Bill Mann's project in California that I wrote the grammar for first, and then Christian [Matthiessen] was taken on. He was doing his Ph.D. in UCLA at the time and they took him on part-time. He extended the grammar, developed it, learnt the basic skills required for text generation, working with a computer; and that fed back immensely, both through him as a person and as a great grammarian, but also through the experience of learning how to write grammars so that they could be processed in the machine. So all the time we've moved out into new directions, new kinds of application, but there's always been a significant feeding back into the theory.

GT - One thing that constantly emerged last week [in the Systemic Linguistics Summer School run by Halliday] were references back to your early work, showing a continuity which seems to me to have been quite marked. There seems to be a constant thread in your thinking: one can go back to the early papers and find things in which the details may have changed, but the basic ideas remain. Would you say that you have essentially been working out ideas that were there in embryonic form from the start?

MAKH - In a certain sense, yes. That's not to say, obviously, that there haven't been shifts. I'll give you one example. One important input 
was the political one, when I was working with a group of Marxist linguists who were trying to develop a Marxist theory of language. I learnt a lot from them, because we were very concerned to work out a theory that would give value to varieties of language that were traditionally neglected. I mean dialects as opposed to standards, spoken language as opposed to written, and learners' languages - children and non-native speakers, emerging languages from ex-colonies, unwritten vernaculars, all these kind of things. We didn't see ourselves as doing something terribly revolutionary; we saw this essentially as being present in European thinking, but needing to be brought together. Now, one example of where I've changed is that I had at that time what you might call a classical Marxist view, which was very much technology driven and therefore seeing language as a kind of second-order phenomenon, where essentially it was reflecting rather than construing. ${ }^{3}$ But there has been a shift, generally, towards what has been characterized as neoMarxist (I never liked these 'neo' labels, but it's certainly not 'postMarxist'). I now want a better account of the balance between the material and the semiotic in human history. And so, instead of seeing language as essentially technology-driven, I would want to see it as a product of the dialectic between material processes and semiotic processes, so the semiotic become constructive - constitutive, if you like. That, I would say, is a fairly important shift. ${ }^{4}$

\section{SFL and other schools of linguistics}

GT - Very broadly, would it seem to you to be fair to characterize the

\footnotetext{
3 The fact that language does not simply 'reflect' social structures but 'construes' them is a fundamental tenet of systemic functional linguistics. The 'reflecting' view assumes that social structures exist and language use merely mirrors them: to take a simple example, we have different ways of talking to social inferiors and superiors because society is organised in such a way that there is often a difference in rank between people who talk to each other. The 'construal' view, on the other hand, assumes that language use not only mirrors social structure but also constructs and maintains it: thus every time someone uses language 'appropriate' for a social superior, they are both showing their awareness of their status and simultaneously reinforcing the hierarchical social system. If people begin using less formal language when talking to social superiors (as has happened, for example, with the near disappearance of 'Sir' as a term of respectful address to men in Britain), they are in effect changing the social structure.

${ }^{4}$ Cf. Pauline Rosenau (1992) Postmodernism and the Social Sciences Princeton, NJ: Princeton University Press.
} 
two main streams of linguistics as isolating and integrating, with yours very firmly in the integrating camp?

MAKH - Yes; if what you had in mind with 'isolating' was the mainstream tradition from Bloomfield via Chomsky in North America, with its insistence on autonomous syntax, with the way that they took language as a thing in itself, rather than as some element in a wider social system and process, then I think that's fair enough.

GT - In the isolating tradition, socio-linguistics and pragmatics, for example, become things you can push aside if you're not interested in them, whereas, within the systemic-functional approach, you can't.

MAKH - That's absolutely it. In a sense, the only reason why that tradition created socio-linguistics and pragmatics was because these weren't in the theory of language in the first place, where they should have been. And I always said that we didn't need a concept of socio-linguistics, because our concept of linguistics always was 'socio'. And similarly with pragmatics: to me this has always been simply the instantial end of the semantics. We don't need a separate discipline. Another dimension of the isolation, of course, is the isolation between system and text. If you're focusing on the system, the text is just data, which has no place in the theory. Then when somebody does want to come and study the text, they do it under a totally different disciplinary banner and both sides lose.

GT - You mentioned earlier that you were outside 'mainstream' linguistics. Clearly there was a time during the 1960's when American structuralist linguistics was aggressively dominant. Did you ever feel like giving up linguistics?

MAKH - Yes, there was indeed! About the mid-60's, when I wrote papers like 'Some notes on "deep" grammar' and 'Syntax and the consumer', I really did try to make contact with the mainstream. And the reaction was just: “Keep out!" I think if I'd been in the United States, I would have got out. I think it was only the luxury of not being in America that made it possible to survive, because so many good people in America were driven out: they just left the field. The work which should have been done, for example, on native American languages was dropped for a whole decade or more. It was discouraging; but, as I say, the Atlantic was between us, so it wasn't quite that bad. And I've always enjoyed the teaching - we always had students who were interested. 
But, on the other hand, I wasn't so bothered, in the sense that it never occurred to me that I had to persuade other people. I was never a missionary; I just wanted to get on with my own work. That was what became more difficult. Just to give you an example, I said just now that in the 60's data were out: the worst thing you could be called was data oriented. It was the really bad word of that decade. If you were data-oriented you were no linguist at all. ${ }^{5}$ But you see, on the other hand, there was [Randolph] Quirk in the next department building up the Survey of English Usage, and he wasn't going to stand for any of that nonsense. I enjoyed working with him and Geoffrey Leech, David Crystal and so on. You weren't completely isolated, but you were shut out from the mainstream of linguistics. My feeling was that it didn't do me much harm but it did a lot of harm to the subject.

HC - But presumably you are happier that you are mainstream now!

MAKH - Well, yes. Although somebody once said to me later on: “Doesn't it worry you, always being out of fashion?” And I said: “There's only one thing that would worry me more, that's being in fashion." In a sense, though, this is a serious point. We all know political parties that do very well as long as they're in opposition!

\section{Critical linguistics}

HC - Earlier you talked about the political aspects of your theory. It seems to me that, among modern linguists within the functional tradition, the one who shows that he is really on your side from the political point of view, not to mention the other aspects, is Gunther Kress. His work has evolved towards a very critical, political, interpretation of the linguistic analysis. How do you see this sort of step towards this more political preoccupation?

MAKH - I see it very positively: I have a lot of interest in and respect for this work. There is a range of work that varies in the extent to which it

\footnotetext{
${ }^{5}$ For example, Chomsky, in a paper published in 1964, dismisses the study of language in use as 'mere data arranging', and makes the claim that a corpus 'is almost useless as it stands, for linguistic analysis of any but the most superficial kind'.
} 
actually engages with language; and I think that the sort of work that Gunther does, and other critical discourse analysts - Norman Fairclough and colleagues on the European continent and elsewhere - is outstanding in the way it does engage with language. There is a tradition which doesn't really engage with language, which is more like a kind of literary criticism where you make your commentary on the text but there's no way in which someone else coming along will get the same result. Now, I think critical discourse analysis stands out in the fact that they do consider language issues seriously. I have argued - and my wife [Ruqaiya Hasan] has done so more strongly because she feels very strongly about this - that they don't do it enough. They still need to locate what they say about language more clearly within a general framework, so that you really see to what extent a text is using the resources of the system, of the potential, in what sort of context of alternatives and so forth. So I think they could go further - and I'm not saying they all have to be systemicists - but in some way making really clear how they are seeing the system. This is the context of that remark I made once: "If you are really interested in the language of power, you must take seriously the power of language." Those are, if you like, the critical observations I would make. But on the other hand I see them very positively. And there are other questions which are not specifically linguistic, which are not necessarily relevant here, but I think it is interesting to ask: What is the underlying social theory? What is the underlying socio-political base of the work? But that's a different question, and it's one that one asks not from the point of view of linguistics, but just from a more general political background.

HC - I should add that the reason for my question was that in Brazil, together with the core of theoretical studies in SFL, there is a big development of research in the area of critical linguistics, and our effort has been to systematically ground research always on language and then go forward with the critical side after that; and so people will welcome your words of support in that respect.

\section{Future perspectives: linguistics and cognition}

GT - Let me take you to the next question. How do you see Systemic 
Functional Linguistics as likely to develop in the next couple of decades? How would you like it to develop? What sort of issues do you think it should be addressing?

MAKH - I hope it will continue to provide a resource for people who are asking all kinds of different questions about language. That seems to me important. What I hope will happen is that, just as the collaboration with educators took place over the last quarter century, a similar development will take place in relation to clinical work, to medical practice, to studies of language pathology, language disorders and so forth. That's much further behind, but it's beginning. I think collaboration between linguists and medical researchers would be very valuable. Another area related to that, which I think now is a tremendous source of inspiration and insight, is neuroscience. I mean the work which is being done on the evolution and development of the brain, since the leading edge is no longer simply the neurology, that is the pathology of the brain, but neuroscience, the actual evolution and operation of the brain. I think that a lot of ideas have been coming in which resonate very well with both our overall model of language and also the model of language development. That now seems to me to make very good sense, but we need to learn a lot more about it. We need people going into modern studies of the brain to see how we can interpret our linguistic findings.

GT - Do you think that at the end through a combination of systemic linguistics with neuroscience you might show that, actually, Chomsky is wrong in his view of how language is learned?

MAKH - Well, I think it depends on which version you take. I think he was wrong, in the first place, in his assessment of the data. He set up a pseudo-problem, by saying: "How can a child learn language with such impoverished data?" But when you actually record what goes on around the child, it's far from impoverished. So that was just not a real question. There's another input from learning theory now: "What makes a language learnable?" I think we can now talk about various features, including quantitative features in our corpus, all kinds of patterns which we didn't see before, which relate to this question of how the child learns, because the child is able to recognize such patterns and build on them. I think we get a sense of at least what some of these patterns are. We are certainly programmed to learn: as Jay [Lemke] once remarked, if children are 
predisposed to learn, adults are predisposed to teach. But you don't have to postulate built-in structural rules: I don't think there is any need for it and I don't think there is any evidence for it - I think Chomsky was wrong there too. And I hope that we'll continue to interact with educators - partly because many of them still have very primitive notions about language, at least in the countries that I know!

GT - Would you say, very broadly, that cognition is perhaps the major new area for SFL, and that in a sense you're finally going below the skin? ${ }^{6}$

MAKH - The question of cognition, I think, is a different one, because nobody has ever denied cognitive processes take place, processes of consciousness which are essentially part of the production and understanding of language. There's no doubt about that. I think the question which interests me is, how do you model these? The reason I don't talk about cognitive modelling is because there seem to me to be two problems with it. What Christian [Matthiessen] has done is to show, very interestingly, how the model of mind and cognition which tends to be foregrounded in much research now is one that is simply based on folk linguistic concepts, mainly deriving from mental processes in the grammar. ${ }^{7}$ And I would add the further point that, if you try to use cognition as a way of explaining language, you tend to be going round in a viciously small circle, because the only evidence you've got for it is linguistic evidence in the first place. So I would say rather that we should take some model of language and use that to explain cognition. That's what the new book by Christian and $\mathrm{me}^{8}$ is all about: we are talking about "cognition", but we call it meaning. These are not contradictory, they're complementary. We want to say that somebody should explore the power of grammatics, as we

\footnotetext{
${ }^{6}$ Halliday has frequently said that he only goes 'as far as the skin' in exploring language. That is, he sees no useful function in speculating separately about cognitive processes that might be involved, since - as he goes on to say - the only evidence we have for them is linguistic in the first place (see his later comments about the concept of the mind being 'misleading rather than helpful').

7 See C. M. I. M. Matthiessen (1998) 'Construing processes of consciousness: from the commonsense model to the uncommonsense model of cognitive science', in J. R. Martin and R. Veel (eds.) Reading Science: Critical and functional perspectives on discourses of science London and New York: Routledge, pp. 327-356.

${ }^{8}$ M. A. K. Halliday and C. M. I. M. Matthiessen (1999) Construing Experience through Meaning: A language-based approach to cognition London and New York: Cassell.
} 
call it, to push "upwards" and interpret cognitive processes as semantic, or (more broadly) semiotic.

GT - Within Chomskian grammar from very early on there was a lot of commentary on his ambiguous use of 'grammar' - whether it was purely a way of describing structures for the linguist, or whether it reflected how language was processed. Is it right, perhaps, to say that we're coming to the point where, with a very well developed model and with more information about the brain, it's possible to start blurring that line?

MAKH - I think it is. I think it's a question of what you put there in the middle or on the other side of the line. Let me put it this way: I would feel that we could go straight from language to the brain, that we don't need to interpose an intermediate level of cognitive processing. I would say that our strongest, our most powerful methodology and theoretical resource is the one that we've developed in relation to language. Essentially language is more accessible and is better explored; therefore let's use the power of the linguistic theory to move in that direction. Maybe we don't need to postulate a mind, or cognitive processes, on the way.

$\mathrm{HC}-\mathrm{By}$ learning more about language, one learns more about the brain, then. And how about the mind?

MAKH - Yes, and by learning more about the brain one learns more about language. The two then meet in the language-brain. The mind disappears - though consciousness remains. The critical concept to me is consciousness, because that is clearly defined evolutionarily. Part of the problem of the mind is: what are you claiming in evolutionary terms? This is why I often quote Edelman, ${ }^{9}$ who follows Darwin. Darwin always said, there's no mysterious entity called mind; as we know more about evolutionary processes, it will fall into place. Now what Edelman is saying is, yes, it has fallen into place. If you do talk about mind in the folk linguistic sense, what is the status of it in terms of the evolution of the brain? It's like entropy, if you like: it's not a thing, it's something you postulate in an explanatory chain. Now I'm not sure we need it. We do need entropy, of course! But mind may be misleading rather than helpful.

${ }_{9}^{9}$ G. Edelman (1992) Bright Air, Brilliant Fire: On the matter of the mind New York: Basic Books. 


\section{Register}

GT - The next question concerns the current focus on patterning at text level. Many people have come into Systemics through text analysis, because they've found it beautifully adapted for that. At that level, you've worked with the concept of register, ${ }^{10}$ but there has been a lot of discussion about the usefulness of the concept of genre. What's your position?

MAKH - The kind of stratal modelling which Jim Martin has introduced involves saying that we have a separate stratum we call genre. ${ }^{11}$ First, on a purely terminological point, I think he slightly misunderstood the notion of register as I originally meant to define it. That's as much my fault as his. But apart from that he's making the point that we need two strata here, above the linguistic system; and he relates this to notions of connotative semiotics - that is, language as the realization of other semiotic systems and processes. ${ }^{12}$ I think it is very powerful, but it's partly a matter of what you are using the model for. I haven't found it necessary; but I'm

\footnotetext{
${ }^{10}$ Register is 'linguistic variation according to use'. In different contexts of situation, people use language in ways that are recognizably different: for example, the language of a news report is different from that of a recipe. This is not just a question of the subject matter (though that is part of it): a whole range of lexicogrammatical choices will be different, often in subtle ways. Most registers do not use 'special' grammar (although there are a few marginal examples, such as newspaper headlines in English, which use some structures that are not used in any other registers). What changes is the whole configuration of choices: in any particular register, there is the likelihood that particular combinations of structures will occur (or will not occur), in a pattern of choices that is not exactly like any other register. As Halliday says later, the probabilities are skewed. To take some simple examples: imperatives are highly unlikely to occur in news reports, but highly likely to occur in recipes; past tense forms are highly likely to occur throughout narratives, whereas scientific articles are more likely to have a high incidence of present tense forms except in the 'Methods' section; and so on.

11 See, for example, J. R. Martin (1992) English Text: System and structure Amsterdam: John Benjamins.

12 Systemic linguistics relies on a stratal model: that is, language is seen as a semiotic system that works at different 'levels' or strata. In Halliday's model, there are three strata, which we can see as going from the most abstract to the most concrete. The semantic stratum (the sets of meanings that we want to express) is realized by the lexicogrammatical stratum (the sets of wordings we use to express those meanings), which in turn is realized by the phonological (or graphological) stratum (the sets of physical sounds and marks that we use to express those wordings). Martin argues that the model should include a fourth stratum above semantics: this is genre, which is then realized by the semantics (in oversimple terms, people have generic sets of purposes to carry out when they use language, and those purposes are carried out by choosing certain meanings).
} 
not doing the sort of work in education that Jim is doing. It's particularly in the educational context that he has found this stratal model useful, and I'm happy with that. These are the sort of arguments that go on between colleagues: some people are comfortable with intention as a theoretical concept and find it helpful, but I'm suspicious of it as something that seems to lead to a circularity in the reasoning. But the overall framework is very close, and I have no problem with the genre model as Jim has developed it: it's extraordinarily powerful, and it's something which teachers have found useful, and which he and his colleagues have found useful both in working with teachers and also in preparing and designing materials and programs.

$\mathrm{HC}$ - Would you agree with the association between genre and the level of the context of culture? If one wants to think about genre, not only as an adequate and acceptable tool if one is working in education, but thinking about it in terms of the theory, would you agree that it could be mapped against the context of culture?

MAKH - Yes, I would. And I suppose that highlights the kind of difference, because to me the context of culture is the system end of the context of situation. I mean these are a single stratum related by

\footnotetext{
13 Instantiation is a key concept in systemic linguistics. Any actual text (an 'instance' of language) is an instantiation of the language system (the 'lexicogrammar'). What this means is that the system does not exist independently of use (although people often talk as though the grammar of the language were a set of 'external' fixed rules). Each time someone uses language, they are both activating the system (or rather, part of it) and, to an infinitesimal degree, changing it. Halliday has explained this relationship between instance and system by comparing it to that between weather and climate. What people are most conscious of is usually the day-to-day weather; but if we look at the patterns of weather from a long-term perspective over a number of years or centuries, we no longer talk of weather but of climate. These are the same phenomenon, but seen in different time-scales. Another way of putting this is that the weather 'instantiates' the climate. Here Halliday is applying the same concept to contexts. A context of situation is an instance: every individual text arises in (and 'construes' - see note 2) a specific context of situation. But contexts of situation tend to recur: we recognize that there are close similarities between, say, one classroom lesson and another, or between one television news broadcast and another. When we get recognizable groupings of similar contexts of situation, those correspond to different registers: we can easily recognize the register of classroom interaction, for example ('Okay, so what does "diffraction" mean? Tim? ... Yes, that's right.'). Halliday is arguing that when we put together all the groupings of contexts of situation that we recognize as actually or potentially occurring in our culture, we have the context of culture - the system of contexts that operates in and constitutes our culture.
} 
instantiation. ${ }^{13}$ Therefore that's the way I would see genre and register, rather than as two strata. But this is something we need to explore, because these are alternative ways of interpreting this phenomenon. But I agree that it is the context of culture that is the environment for genre - that's not in dispute. I think it is a question of whether you see genre as a separate stratum or as sub-system on the stratum of (discourse-) semantics.

GT - But then if we take a more practical angle, the term genre is sometimes used when you are looking at the text as a whole, without necessarily projecting right up onto the culture. Do you find a need for a term to talk about how texts utilize register resources but within a particular overall organisation or patterning?

MAKH - I've always seen that as a part of the notion of register. Let me put it this way. Suppose you collect instances: if you stand at that end, then you will arrive at groupings of text types, bodies of texts that are in certain respects like each other and different from others. If you then shift your observer position to the system end, then that text type becomes a subsystem, and that's what we call register. That's the way I would see it: it's the semantic analogue of what in the context of culture would be an institution of some kind, a recognized body of cultural practice, or institutionalized cultural forms; and that semantic entity, to me, would fall within the concept of register. ${ }^{14}$

GT - You have made extensive use of the concept of marked versus unmarked choices, ${ }^{15}$ more recently using computational means to arrive at a new perspective in terms of probabilities. In what ways do you feel

\footnotetext{
${ }^{14}$ For an overview of register and genre, see C. M. I. M. Matthiessen (1993) 'Register in the round', in M. Ghadessy (ed.) Register Analysis: Theory and practice London: Pinter. For a critique of Martin's position, see R. Hasan (1995) 'The conception of context in text', in P. Fries and M. Gregory (eds) Discourse in Society: Systemic-functional perspectives Norwood, NJ: Ablex.

15 As Halliday goes on to explain, an 'unmarked' choice in the grammar is the one that is taken if there is no particular reason for doing anything else. A 'marked' choice is one that is taken when there is a particular contextual reason. For example, 'I went to London on Friday' has the unmarked word order (Subject first), and it is hard to predict what the surrounding sentences will be like. On the other hand, 'On Friday, I went to London' has a marked word order, and would most likely occur in a context where at least one of the other sentences started 'On Monday/The following day/etc. .... In other words, the speaker or writer is setting up a particular framework based on time sequence, which is signalled by highlighting the phrases of time by moving them to the front of the sentence.
} 
that this changes our view of language? More particularly, does the fact that probabilities and therefore markedness vary within different registers (and across languages) raise problems with the idea of a functional grammar for a language: should we be thinking rather in terms of functional grammars?

MAKH - Let me join up the notion of marked and unmarked, probabilities and the corpus. They are really all related, and I see the corpus as fundamental in shifting the whole orientation of linguistics, because for the first time linguists have data. They haven't had data before; and this will enable them, I hope, to leap over a few centuries and move into the 21 st century as a true science. This includes the quantitative dimension, which to me is important. The quantitative basis of language is a fundamental feature of language: I think that a grammatical system is not just a choice between $\mathrm{a}$ or $\mathrm{b}$ or $\mathrm{c}$ but $\mathrm{a}$ or $\mathrm{b}$ or $\mathrm{c}$ with certain probabilities attached - and you get these probabilities out of the corpus. ${ }^{16} \mathrm{I}$ think there is some misunderstanding here. People have sometimes said, well, any text is in some register or other, some genre or other, so it doesn't make sense to talk about the global probabilities of language. This is total nonsense. It makes perfect sense: that argument is rather like saying that just because every place on the earth is in some climatic zone or other, it doesn't make sense to talk about global climate; but of course it does. Global climate is global climate, it has certain features, certain probabilities, which we then look at more delicately when we get to the climate of Brazil or Britain or whatever. It is the same with language: it is essential to be aware of the notion of global probabilities in language. Now that the corpus is big enough, we can get at them, because the corpuses now range

\footnotetext{
${ }^{16}$ For example, one system of grammatical choices is the choice between present, past and future tense. Traditional grammars simply record the fact that these three basic options exist. A corpus, however, can reveal that, if we look at the whole range of language use (the 'system'), people actually choose present tense more often than past tense, and past tense more often than future tense. This is as important a fact about the grammar as the existence of the three options. It is against this background, for example, that we can look at the skewing of the probabilities that Halliday mentions. To return to an example in note 8 above, the fact that past tense forms are the most likely choice in narrative is one of the features that make narrative distinctive, precisely because this does not follow the overall pattern of tense choices across all the uses of language. This issue is discussed in M. A. K. Halliday and Z. L. James (1993) 'A quantitative study of polarity and primary tense in the English finite clause' in J. M. Sinclair, M. P. Hoey and G. Fox (eds) Techniques of Description: Spoken and written discourse London: Routledge, pp. 32-66.
} 
across lots of different registers, spoken and written discourse and so forth. So we need those global probabilities, but we need them as the kind of baseline against which we match probabilities in particular sets of texts, different registers. Indeed, I would define a register as being a skewing or shifting of the probabilities, because not many registers actually close off bits of the system. What they tend to do is to shift the probabilities, so it is the same system but with a different set of probabilities, not only in the vocabulary but also in the grammar.

Now, with marked and unmarked the problem is that we tend to define it in half a dozen different ways, and we need to get clear what we mean when we talk about marked and unmarked terms in systems. You can relate this to probabilities, and it may even turn out in the long run that we can define it in terms of probabilities; but I don't think we should do that yet. I think we should be thinking of it in semantic terms. Of course, we have the concept of formally marked, by morphological means: that's important, but it's easy to recognize and it doesn't necessarily go with semantic marking. The real concept that we can use is that of the unmarked choice, or unmarked option, in a grammatical system, which is a kind of default choice. I used to find this very useful in language teaching, because I could say to the students: "This is what you do, unless you have a good reason for doing something else". For example, you find out what the language does with its unmarked Theme, if it has a Theme, and you say, right, that is your basic option, but here are the conditions which would lead you to do something else. ${ }^{17} \mathrm{I}$ think it is a useful concept: it is linked to probabilities but I wouldn't want yet - or maybe ever - to define it in probabilistic terms.

GT - Within a register you would use what otherwise would be a marked Theme, not as a choice open to an individual writer - in a sense there's very little choice, you've got to use this kind of Theme - but because

\footnotetext{
${ }^{17}$ In Systemic Functional linguistics, Theme is the first 'content' element in the clause. It represents the 'starting point' of the clause, and serves to establish the framework within which the clause is to be understood. The examples in note 12 above are in fact to do with the Themes: the use of a marked Theme such as 'On Friday, I went to London' signals to the hearer that the speaker is moving to the next frame in the time sequence. If the following Theme is then unmarked (' $\mathrm{I}$ visited the National Gallery'), it signals (amongst other things) that we are still in the same time frame of 'On Friday'.
} 
of that register's conventions, which have evolved in response to a particular communicative need. I think that's an issue that worries some people: they're finding that in a particular register, you take a certain option when there is no good reason not to, even though in the language as a whole that would be otherwise be a marked choice.

MAKH - That's exactly what I would say. They ought not to be worried about it, it is just a point that needs to be made explicit. There are two steps: one is to say that, in this register, what would in general be a marked Theme, or mood or whatever, becomes the unmarked option here. They shouldn't have a problem with that. The second step is to say: "Can we explain this?". What happens in general is that if you go back into the history you can, but things get ritualized, so that you may have to say, look, in terms of contemporary uses it doesn't really have any function. That's the way it evolved, and we can see why it evolved that way. It's best to do that if possible because adult language learners like explanations they're not satisfied just with the idea of ritual. But you may have to say that, just as you have to learn there are irregular verbs in Portuguese or English or whatever, so you have to learn that there are funny things that go on and we can't explain them all. But in cases like these which are clearly semantic choices you can usually see where the unmarked option came from.

HC - As you say, this is specially useful in the context of learning languages. When people raise these issues back home in Brazil, they usually have this sort of issue in the background. We do a lot of teaching of languages for specific purposes, and of course if you are doing LSP you are often dealing with very specific registers. For example, you may have to teach Brazilians how to interact successfully in discussions groups on the Internet, which involves informal interaction in writing. A student of mine found that the vast majority of requests for information will be in the declarative form introduced by expressions of politeness, like "I would appreciate it if you could tell me", or "I would be specially thankful if you let me know". The frequency of this marked use of the declarative is very high in that specific type of communication, and if you're teaching your students that kind of language you want an explanation for it.

GT - Yes, there are two levels. You can simply say: “This is what you 
do"; or you can talk through it, raising their language awareness, getting them to think about what it is in this new medium or mode of communication which means that that use is going to occur. I very often find students respond well to that approach and they remember because it makes sense.

MAKH - I agree, it is much more memorable if you can make it make sense. I mean, we all know that as language teachers we sometimes invent explanations!

\section{Practical issues of analysis}

$\mathrm{HC}$ - The recognition criteria for Theme are one of the few practical issues within Systemic Functional Grammar that have aroused disagreement. Do you see any reason for changing your view that Theme extends as far as the first experiential constituent of the clause, and no further?

MAKH - I'm interested in this question, and I know that some people have preferred to take the Theme beyond what I would: to include the Subject, for example. Now I think this is worth exploring further. There are various reasons why I did what I did, one being intonational. It is generally true in our early recordings that in cases when a clause is broken into two information units, the break typically comes - in well over 50\% of cases - at the point where the break between Theme and Rheme as I defined it comes: in other words, it would not include the Subject that follows a Complement or Adjunct. I have also said that I don't see the point of extending it to the following Subject because the Subject's got to come there anyway. Once you've chosen a marked Theme, you've got no more choice in the order, so you don't need to explain the Subject. So I'm

\footnotetext{
${ }^{18}$ For a fuller discussion of Theme, see R. Hasan and P. Fries (eds) (1995) On Subject and Theme: $A$ discourse functional perspective Amsterdam \& Philadelphia: Benjamins.

19 Transitivity in SFL refers not just to the verb, but to the way the experiential 'content' of the clause is expressed. It is a way of describing the processes and the participants being talked about. So, in a clause like 'He boiled the water rapidly', we have a material (physical action) process of boiling, involving an Actor 'he' (the entity doing the process) and a Goal 'the water' (the entity affected by the process), plus a circumstance 'rapidly'. This analysis brings out the similarities between this clause and a clause like 'She chopped the carrots finely'. But we can also look at the clause from a different perspective, the ergative one. If we compare the clause with 'The water
} 
not convinced by the motivation for extending the Theme; but it is something to explore, especially now that we've got the corpus: let's look at what happens in terms of the function of Theme in discourse. We need discourse reasons for claiming that Theme extends further, and I think that the issue is still open. But I admit that I have not yet been convinced of the need for it. ${ }^{18}$

HC - In your Introduction to Functional Grammar you argue that transitivity and ergativity are alternative perspectives on processes. ${ }^{19}$ Would you want to say that this applies to any clause?

MAKH - I think this is a very interesting point. It is a typical kind of complementarity. I used to cite the old controversy from Newton's time about the nature of light: was it particle or wave? You could say that there is a single set of phenomena which range along a cline, and the phenomena at one end of the cline are better explained in terms of an ergative model, and the phenomena at the other end are better explained in terms of a transitive model. That after all applies to grammar and lexis. It's a cline, but there's one end where you do better using grammatical theory, and the other end where you do better writing a thesaurus or a dictionary. Now the next step could be to say, OK, but if that is the case, aren't these essentially different phenomena? Here of course I'm thinking of Kristin Davidse's work: ${ }^{20}$ she has taken that step and I thoroughly applaud it. I had just said that there is one set of phenomena here, and there are reasons for looking at it from two different ends. I didn't take it further and say that I want to set up transitive and ergative as different classes of process. She took it that far, and I think it's quite fair to do that. It's a normal situation in complementarities of this kind. There are many of them in language - for example, tense and aspect, which are essentially complementary models of time. In some language systems, like Russian

\footnotetext{
boiled rapidly', we have the same verb but in a different transitivity structure - 'the water' is now the Actor. However, it is clear that in both cases the water is the 'location' of the boiling; the difference is that in the original clause 'he' is represented as causing the boiling to happen in that location. We can bring out the underlying similarity by using ergative labels: in both cases 'the water' is Medium (the entity in or through which the process comes into being), while in the first clause 'he' is the Agent (the entity causing a process to happen). For a full discussion, see Chapter 5 of M. A. K. Halliday (1994) An Introduction to Functional Grammar London: Edward Arnold.

${ }^{20} \mathrm{~K}$. Davidse (1992) 'Transitive/ergative: the Janus-headed grammar of action and events' in M. Davies and L. Ravelli (eds) Advances in Systemic Linguistics London: Pinter, pp. 105-135.
} 
and other Slavonic languages, it's clear that they are both there, and it's clear which is which. In English, on the other hand, they are more problematic. I personally think that to talk about what people call perfective and continuous as aspect is not very helpful, because there is a much better model for these - secondary tense; and the aspect just comes in the nonfinites. But you have to see which gives you a more powerful picture - and again thanks to the corpus we now have a lot more evidence we can look at.

In principle, coming to the level of structure, I like to do both, to give one interpretation in terms of transitivity and one in terms of ergativity; but that's because in the way I developed it it seemed to me you were making different kinds of generalizations: the ergative perspective helps you in seeing where all the process types are alike, whereas the transitive perspective helps you in seeing the differences.

\section{Complexity and computer-aided analysis}

HC - Just one last question about the complexity of the theory. I see a paradox between the theory being so complex and the vast amount of data we have access to these days. We want to be able to deal with all this data with the help of computers, but there is a kind of mismatch: the theory is good because it's complex, but on the other hand it is difficult to use it, because computers ...

$\mathrm{MAKH}-\ldots$ are very simple!

$\mathrm{HC}-\mathrm{Yes}$, too simple for the theory.

MAKH - As you know, I defend the complexity of the theory, because we are talking about a very complex phenomenon, and it doesn't help anyone if you pretend it's simple. We have to build that complexity in, and what you're trying to do is to manage it. We hear a lot about this today, complexity management, and this is what we're dealing with. Five or six years ago I was working with Zoe James on the computer at Birmingham [see note 15]. We looked at the tagger, but we didn't use it because it was precisely the things we needed to know that it was very bad at. The parsers were still too slow: we were working with a million and a half clauses, so there was no way that we could rely on a parser. What we 
were looking for - and Zoe was brilliant at thinking in these terms was a kind of pattern matcher, which could give us just enough evidence to identify the features we were interested in. Zoe got it to the right level of accuracy for polarity, tense and modality; but we never cracked the voice code - we were working on active and passive, and we never got it to quite the level where we thought that we had enough accuracy for our results to be valid. But that is just a matter of work. I had to leave, and she had to leave too, and so far no-one else has taken it up. Of course, the new parsers are a lot quicker and more accurate now; but in any case you need to identify your task closely and then see what part of the theory you need and use this for pattern matching. It's a question of deciding which area you're interested in, and then thinking, let's see what tools I need in order to get this out of the corpus. It may involve a total parse, or it may be something in between. It may be something that the tagger will help you with, but usually I'm looking at larger chunks, so word tagging hasn't been terribly helpful. Strategically you do need to define your task very precisely.

In a sense, this goes for text analysis generally, whether it is human or machine aided: you can't survey a text completely, because you'd be there until the end of the year working on one sentence. What you try to do is familiarize yourself with the text and the possibilities. This is something that is hard to teach students, because there is no algorithm for it: you need to get a sense of how you take in a text, then you say, I think that modality would be interesting here, or we really need to look at process types in this text, or whatever. You keep all the resources of the grammar in front of your eyes, and select those you think will be most revealing. You're not always right, of course! But otherwise you could have an endless task.

HC - Well, thank you very much for your time. 